\title{
CONVERGENT TECHNOLOGIES AS CONCEPTUAL BASIS FOR FORMATION OF POWDER INDUSTRY IN AGRIBUSINESS
}

\author{
Muhtar Kerimov' ${ }^{1}$ Irina Belinskaia ${ }^{2}$, Oleg Ognev ${ }^{1}$ \\ ${ }^{1}$ Saint-Petersburg State Agrarian University, Russia; ${ }^{2}$ Leningrad State University named after \\ Alexander Pushkin, Russia \\ kerimofmuhtar@yandex.ru, belinska@yandex.ru, ognew.og@mail.ru
}

\begin{abstract}
The active introduction of new technologies, including those based on the application of the principles of nano-grinding, can significantly reduce energy consumption in the production of agricultural products. The scale of such developments in the world suggests the need to create a scientific concept that forms a unified systematic approach to the use of promising technologies for grinding solids and materials. To solve this problem, the authors have developed a technology for crushing agricultural raw materials, and also designed a working body for a disintegrator-type grinder. The studies carried out by the authors on the use of nanopowders in the production of feed for cattle, as well as mineral fertilizers, made it possible to formulate the goals, objectives and main directions of development of the powder industry based on the use of convergent technologies, as well as mechanisms and ways to achieve these goals. Implementation of the developed concept is of great fundamental and practical importance. It will allow to ensure, in the medium term, the transition of the economy of the agricultural sector to the large-scale application of technologies for nanomilling of raw materials, secondary raw materials and waste processing, which will significantly reduce production costs. A decrease in costs on the scale of the regional economy will be facilitated by: decrease in logistics costs for raw materials in the form of crushed microfractions; increase in productivity and a corresponding increase in profitability by improving the properties of particles, increasing their surface as a result of the use of grinding technologies; improving the quality characteristics of agricultural products.
\end{abstract}

Keywords: nanopowders, agribusiness, energy consumption, processing, grinding.

\section{Introduction}

The creation and development of the powder industry meets the strategic objectives aimed at raising agricultural production, the food industry, as well as increasing the in-depth processing of organic raw materials, reducing the loss of agricultural products, reducing the cost of building materials, improving the quality of food.

Dynamic self-grinding mills of various designs developed and in operation have reached the maximum values for productivity and minimum energy consumption. This is due to the fact that the designs of existing dynamic self-grinding mills are based on the kinetic energy of the rotating rotor, which depends mainly on the speed of its rotation, which cannot exceed a certain critical value. At the same time, it should be noted that the tendency to increase the productivity of grinding by installing more powerful drives on known grinding equipment necessarily leads to a decrease in their reliability and an increase in capital costs [1,2,3].

It is known that approximately only $0.1 \%$ of the energy used in grinding is used to break down brittle materials. The remaining $99.9 \%$ is converted from mechanical energy to heat. These energy losses are unavoidable when brittle materials are destroyed by compression. This illustrates the benefits that could be obtained by developing a method for grinding the material with the direct use of tensile stresses.

In the agricultural sector, they are widely used [4,5]:

- jet shredders manufactured by Canadian Electric Company, Ltd (Canada);

- vibrating mills manufactured by Klöckner Humboldt Deutz AG (Germany);

- centrifugal shredders manufactured by SBM Wagender GmbH (Austria).

A correct understanding of the physical nature of the grinding processes and a well-founded methodological system approach to the study make it possible to adequately describe them and, based on mathematical models, develop methods for solving, optimal design and control.

The main questions that are raised in the study of the physics and mechanics of grinding are the following: the mechanism of the process, the change in the size of raw materials and energy efficiency. 


\section{Materials and methods}

One of the technical solutions that allow to reduce specific energy consumption are designs that use closed-loop mechanisms, in which the phenomenon of energy circulation occurs. This technology allows for an additional force effect on the pieces of material during the grinding process and will contribute to their more intense splitting, abrasion, and opening of particles at the atomic and molecular level, leading to lower energy consumption with more significant results. Hypersonic grinding by the method of quantum aerogravity technology for the production of powders has shown the applicability and usefulness of this direction in practice. To date, the best indicators were obtained by freeze-drying (sublimation) [2,6,7]. With the development and introduction of a new grinding technology, a completely new method of dynamic drying in combination with simultaneous grinding becomes available.

A distinctive feature of the result of the application of nanotechnology grinding is the interaction with the fields of science that work with matter at the atomic and molecular level. Thanks to the latest technologies, a fundamentally new technique has been developed - rapid penetration of substances and trace elements into the deep layers [2]. The use of nanopowders leads to an increase in the digestibility of the components by the animal body, increases their indicators, including the biological activity of the product by increasing the surface area of the particles and intensifying the process of extracting useful substances. As a promising way to implement this task, we propose a circuit solution that provides for the rotation of particles in a closed space at a speed sufficient for it to fly apart under the action of centrifugal force. The theoretical energy consumption required to enable this rapid rotation is only a small fraction of the energy required to grind components in existing plants. This technology is based on the grinding of raw materials by forming two oncoming flows with a given speed of movement of raw materials in the flow up to $700 \mathrm{~m} / \mathrm{s}$ with the possibility of collision of raw material particles in a limited area. The method provides for continuous mechanical opening of the capillaries of the solid parts of the processed raw materials with simultaneous evaporation of the moisture released from the capillaries. These capillaries in the form of a shell of a vapor-air mixture protect each dried particle from the effects of a thermal agent, which has a beneficial effect on the productivity of the plant and the quality of the final product [1].

The working body designed by us for the disintegrator type shredder, consisting of two drums, is shown in Fig. 1.

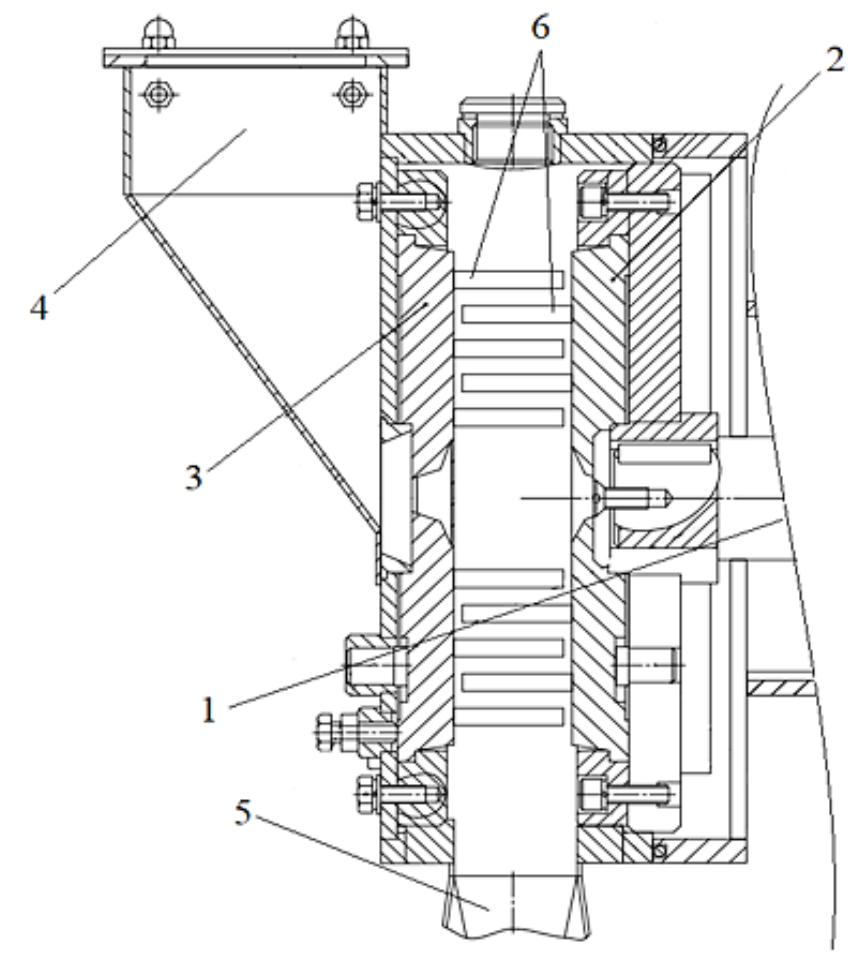

Fig. 1. Working body of the disintegrator type shredder: 1 - shaft; 2, 3-drums; 4 -loading funnel; 5 - unloading funnel; 6 - fingers - beat 
One of the important factors of technology implementation in the production process is the ease of its integration into automated production lines.

The distinctive features of the use of this grinding technology are [3]:

- the structure is climate-resistant and vibration-resistant, can be mounted without a frame and can be integrated into any production line, if necessary, suspended on a stretcher, easy to maintain and does not require special operator training;

- compact and light weight design, remote control and operation in the field (for example, in the form of a self-propelled installation);

- versatility, allowing for the grinding process of virtually various materials, from the metallurgical, chemical and building materials industries to the food industry, agriculture and waste processing industries;

- low maintenance costs combined with high specific productivity per unit of space occupied and electricity consumed;

- modular design of the equipment combined with a variety of layout solutions;

- easy to carry out scheduled preventive maintenance;

- adaptability of the installation to explosive technologies;

- grinding in an ionized electromagnetic field, in the ultrasonic range.

With regard to the process of development of the powder industry, it is necessary to identify the following goals and objectives:

- modernization of existing production facilities that use powdered concentrates in their process chains;

- organization of construction of fundamentally new production facilities for the technology and method of preparation of dry powder concentrates;

- increasing the degree of in-depth processing of agricultural raw materials, fertilizers, premixes, and building materials;

- reducing agricultural production losses, improving the environment;

- improving the quality of food, functional food items, and molecular cuisine;

- introduction of new competitive products made in the form of fine powders to the market;

- reduce logistics and transportation costs by significantly reducing the volume of raw materials used by grinding them.

In the perspective of its development, the grinding technology will expand the possibilities of both waste-free production and recycling of waste in the field of the food industry, construction and industrial sectors, agricultural complex and agriculture of the region $[8,9]$.

\section{Results and discussion}

\section{Food products}

The demand for food powders in Russia, according to expert estimates, is 35000 tons per year of ready-made, balanced food products from powders -24000 tons per year. The creation of the powder industry will ensure the effective satisfaction of the population with products made from live food powders (Pulvisvita). The industry should become a link and coordinator of relations between the scientific community, manufacturers and consumers of food powders in the countries.

Special grinding at the molecular level allows to achieve new, including medicinal properties of products. The powder concentrate preserves all the useful substances of the raw material as much as possible and makes their regular use as convenient as possible. The fine (fine) structure and large surface of the powders helps neutralize and remove metabolic products, toxins, bacteria and heavy metals from the body. But the most important thing is the more affordable extraction of biologically active and useful substances from such powders by 2-4 times, in contrast to the raw materials [3].

A disintegrator-type shredder is used to produce nanopowders. The functioning model of the developed shredder is shown in Figure 2. 


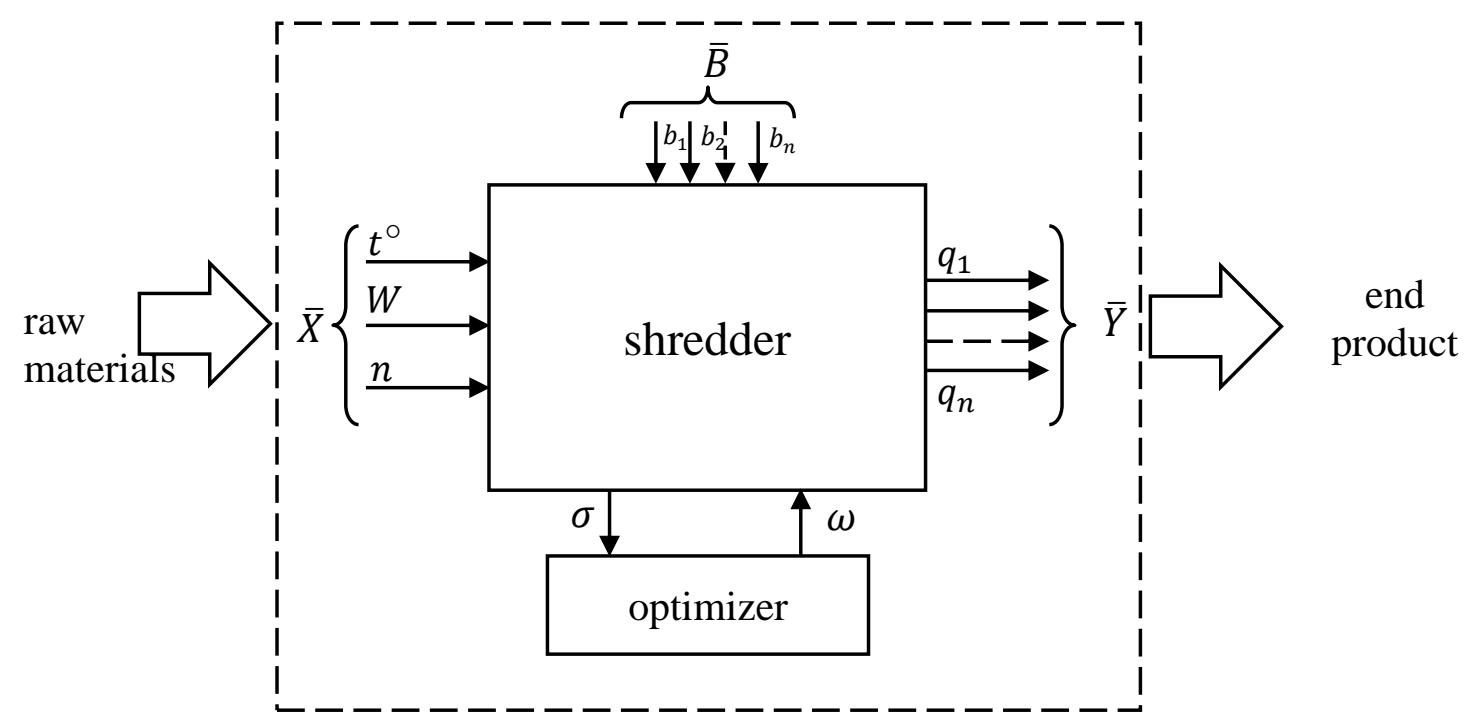

Fig. 2. Model of the powder manufacturing technological process functioning:

$\vec{X}$ - vector-function of input parameters; $\vec{B}$ - vector-function of unmanaged parameters;

$\vec{Y}$ - vector-function of output parameters; $t$ - temperature, ${ }^{\circ} \mathrm{C} ; W$ - air humidity (ambient), \%;

$n$ - disk rotation speed, $\min ^{-1}$

The components of the output process are the quality indicators of the resulting product.

The optimizer analyzes the quality of the disintegrator operation by the degree of the material dispersion $\sigma$ and sends a control signal to the system in the form of $\omega$ (the speed of rotation of the disks), when the values of $\sigma$ exceed the established technological tolerance.

Studying the characteristics of powders obtained using this technology in SPbSAU, a significant increase in the content of trace elements and macronutrients in them was found in the laboratory than in the raw materials and analogues.

The characteristics of the product composition produced by nanotechnology are presented in Table 1.

Table 1

\section{Comparative characteristics of the trace element composition of buckwheat flour produced by nanotechnology}

\begin{tabular}{|l|c|c|c|}
\hline \multicolumn{1}{|c|}{ Indicator name } & $\begin{array}{c}\text { Buckwheat } \\
\text { flour }\end{array}$ & $\begin{array}{c}\text { Buckwheat flour } \\
\text { produced by } \\
\text { nanotechnology }\end{array}$ & $\begin{array}{c}\text { Daily } \\
\text { requirement } \\
\text { for 1 person }\end{array}$ \\
\hline Protein, \% & 10 & 20.3 & - \\
\hline Potassium, mg per 100g & 205 & 670 & 1800 \\
\hline Sodium, mg per 100g & 15 & 10 & - \\
\hline Manganese, $\mu \mathrm{g}$ per 100г & 760 & 2700 & - \\
\hline Copper, $\mu \mathrm{g}$ per 100g & 370 & 900 & 3500 \\
\hline Zinc, $\mu \mathrm{g}$ per 100g & 1090 & 6800 & 15000 \\
\hline Phosphorus, $\mu \mathrm{g}$ per 100g & 343 & 300 & 1200 \\
\hline Iron, mg per 100g & 1.8 & 4.29 & - \\
\hline
\end{tabular}

The structure of the substances is porous, they are easily dissolved in a liquid medium, the product is easily absorbed, due to this, the need for saturation of the product in comparison with the usual portions is 4-5 times less. This technology allows us to achieve high-quality indicators in microbiology, without changing the organoleptic characteristics of the product.

The composition of the powder on the example of the additive "Kedrokorm" obtained in this way is shown in Fig. 3. 


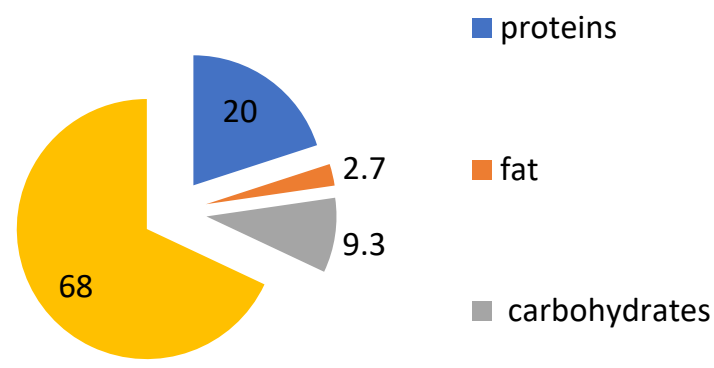

Fig 3. Composition of the feed additive "Kedrokorm"

\section{Feed additives}

The main trends in the industry are the consolidation of production and digitalization. At the same time, the consolidation of production, observed in recent years, naturally continues. In the field of agriculture, there are breakthrough processes in the field of active development of digital tools. One example is the introduction of enterprise performance monitoring programs, such as artificial intelligence for dairy farms and many others. Their use significantly increases the profitability of production (significantly reducing costs) and the accuracy of data and forecasts for the future. Therefore, this trend will only grow in the coming years. Digitalization of agriculture will inevitably bring with it transparency as the new norm of the market. It will include both transparency of the composition (raw materials, components) and origin of feed, and transparency of pricing. The advantage will be given to market players, who adapt to a fundamentally new competitive environment earlier than others $[10,11]$.

In the field of feed for cattle, the authors developed an additive-a complex of additional nutrition from the shell of a cedar nut, which is a finely ground substrate, a monoproduct containing lipids, carbohydrates, protein, macro - and microelements, vitamins F and R. Recommendations for its use in the composition of compound feeds for farm animals were developed by the Department of Feeding of Farm Animals of the St. Petersburg State Agrarian University. This drug was tested in several farms of the Leningrad region with a study of up to five thousand heads of cattle. During the entire testing period, no contraindications were identified (Table 2).

Table 2

Results of using the feed additive Kedrokorm

\begin{tabular}{|l|l|l|l|}
\hline Object & \multicolumn{1}{|c|}{$\begin{array}{c}\text { Period } \\
\text { use } \backslash \text { dose }\end{array}$} & Intermediate result & \multicolumn{1}{c|}{ Control result } \\
\hline Calves & $\begin{array}{l}\text { From 10 days } \backslash 100 \\
\text { mg per 1 kg of live } \\
\text { weight per day }\end{array}$ & $\begin{array}{l}\text { Restoring the } \\
\text { function of the } \\
\text { gastrointestinal tract, } \\
\text { reducing the } \\
\text { recovery time of sick } \\
\text { calves by 2-3 days }\end{array}$ & $\begin{array}{l}\text { Activation of mobility, improvement of } \\
\text { growth and development; } \\
\text { the effectiveness of the additive for } \\
\text { gastrointestinal diseases of newborn calves } \\
\text { with symptomatic diarrhea was 90.0\%, } \\
\text { versus 60.0 - 80.0\% in comparison with } \\
\text { known agents (pectosorbin, antidiarin), also } \\
\text { of plant origin. }\end{array}$ \\
\hline $\begin{array}{l}\text { Little } \\
\text { chickens }\end{array}$ & $\begin{array}{l}\text { From 10 days } \backslash 100 \\
\text { mg per 1 kg of live } \\
\text { weight per day }\end{array}$ & $\begin{array}{l}\text { Prevention of } \\
\text { gastrointestinal } \\
\text { intestinal diseases }\end{array}$ & $\begin{array}{l}\text { Normalization of metabolic processes, } \\
\text { acceleration of growth and development of } \\
\text { up to 7\% of chickens compared to the } \\
\text { control group }\end{array}$ \\
\hline Cows & $\begin{array}{l}\text { From 10 days } \backslash 100 \\
\text { mg per 1 kg of live } \\
\text { weight per day }\end{array}$ & $\begin{array}{l}\text { Increasing the daily milk yield up to 1.5 } \\
\text { liters and improving its taste and milk fat }\end{array}$ \\
\hline Chickens & $\begin{array}{l}\text { From 10 days } \backslash 200 \\
\text { mg } \\
\text { per 1 kg of live } \\
\text { weight per day }\end{array}$ & - & $\begin{array}{l}\text { A positive effect on the bird itself, an } \\
\text { increase in egg mass by 8.0\% and an } \\
\text { increase in shell thickness by 7.9\%. }\end{array}$ \\
\hline
\end{tabular}




\section{Fertilizers}

The payback of mineral fertilizers is reduced due to the reduction of work on chemical land reclamation. It is also necessary to take into account such factors as the return of food elements to the biological cycle when selling grain, etc. At the same time, Russia has the largest reserves of peat in the world, and today peat is both the restoration of soil fertility, and an innovative component of agricultural production, and sources of heat and energy, and improving environmental protection.

Taking into account the availability of raw materials and the volume of the raw material base, this direction has prospects in the field of processing top peat into fertilizers for local use, so that the costs of logistics and transportation do not increase the costs of processing in general. At the Institute of Peat (St. Petersburg), studies were conducted on the content of protein, amino acids, micro - and macronutrients in its powder concentrate. The acids in the composition of the upper peat have antiseptic properties and good filtration, humic acids are present in sufficient quantities, which are used as a natural filter against soil contamination with heavy metals and radionuclides. The demand for peat as a fertilizer is largely due to the high content of humic substances in it, which account for from $20 \%$ to $70 \%$ of the mass.

Peat soils are among the most potentially fertile. They consist of $80-90 \%$ organic matter, whereas in chernozems the humus content is 6-8\%, in podzolic soils $1.5-2.5 \%$. Resource-saving integrated peat management deserves attention and should be provided as an integral part of environmental management measures in the region. The application of the technology of grinding the upper layers of peat can bring additional positive results when fertilizing the fertile layer.

Currently, research is being conducted in the above areas. On the example of additives from the shell of cedar nuts and buckwheat sifting, crushed by the technology of hydrosonic grinding, an increase in useful substances, in comparison with the initial raw materials, for the most part, positions several times. The comparative analysis of the trace element composition of buckwheat was carried out in the Russian Scientific Center "Applied Chemistry" and the testing laboratory of the St. Petersburg State Chemical and Pharmaceutical Academy (Table 3).

On the example of cedar shells, it can be noted that farmers use not even crushed nut shells as mulch. The use of cedar shells is justified by the fact that it prevents the growth of weeds, protects the soil from erosion, dehydration, salinization and deep freezing. Pine nut shells are effective against fungi and insects that harm plants. The content of phytoncides and flavonoids in the raw materials allows to create a bactericidal barrier around the plantings. The use of this mulch contributes to the appearance of earthworms, the formation of useful microflora in the root system.

In addition, as additives and fertilizers, it is possible to use microdispersed powders from agricultural waste, such as eggshells, hogweed, tree bark, humus, seeds and fruit cake.

Comparative analysis of the microelement composition of buckwheat

Table 3

\begin{tabular}{|c|c|c|c|}
\hline \multirow{3}{*}{ Name of indicator } & \multicolumn{3}{|c|}{ Product name } \\
\hline & \multicolumn{2}{|c|}{ Kedroslav } & Cedar nut shell \\
\hline & Average value & Limits & Average value \\
\hline Appearance & \multicolumn{2}{|c|}{$\begin{array}{l}\text { Fine powder brown } \\
\end{array}$} & Small pieces of brown \\
\hline Bulk weight, $\mathrm{g} \cdot \mathrm{m}^{-3}$ & 0.499 & - & - \\
\hline Humidity, \% & 8.2 & - & - \\
\hline Components: & & & \\
\hline 1 Lipids, \% & 5.4 & $4.06-8.1$ & \\
\hline 1.1 Acids: & 2.05 & 1.1-3.0 & \\
\hline - resinous; & 0.02 & $1.01-0.03$ & \\
\hline - fatty, of which & 2.03 & $1.09-2.97$ & $\begin{array}{l}2.2 \\
0.8\end{array}$ \\
\hline Unlimited: & 1.22 & $0.65-1.78$ & 0.8 \\
\hline Oleinovaya & 0.73 & $0.4-1.06$ & 0.5 \\
\hline Linoleic & 0.3 & $0.1-0.5$ & \\
\hline Linolenic & 0.19 & $0.1-0.28$ & \\
\hline Limit & 0.91 & $0.8-1.02$ & \\
\hline
\end{tabular}


Table 3 (continued)

\begin{tabular}{|c|c|c|c|}
\hline \multirow{3}{*}{ Name of indicator } & \multicolumn{3}{|c|}{ Product name } \\
\hline & \multicolumn{2}{|c|}{ Kedroslav } & \multirow{2}{*}{$\begin{array}{c}\text { Cedar nut shell } \\
\text { Average value } \\
\end{array}$} \\
\hline & Average value & Limits & \\
\hline 1.2. Neutral substances, $\%$, of which: & 3.35 & $3.05-5.1$ & \\
\hline Fatty alcohols $\left(\mathrm{C}_{20} \div \mathrm{C}_{22}\right)$ & 1.14 & $1.04-1.7$ & 1.4 \\
\hline Campesterol & 0.8 & $0.6-1.0$ & 0.7 \\
\hline Sterin & 1.0 & $0.8-1.8$ & 0.4 \\
\hline Styrene & 0.06 & $0.04-0.08$ & \\
\hline$\sum X$ & 0.35 & - & \\
\hline 2 Flavonoids, $\%$, of which & 0.9 & $0.6-1.1$ & \\
\hline Anthocyanins & 0.82 & $0.65-1.0$ & 0.4 \\
\hline Catechin & 0.08 & $0.06-0 . .1$ & \\
\hline 3 Tannids, $\%$ & 3.3 & $2.3-4.7$ & 1.8 \\
\hline 4 Polycondensed flavonoids, $\%$ & 0.45 & $0.3-0.6$ & \\
\hline 5 Protein, \% & 6.2 & $5.5-6.9$ & 5.5 \\
\hline 6 Carbohydrates, \% & & & \\
\hline Polysaccharides: & 57.9 & & \\
\hline Fiber in terms of $\alpha$-cellulose & 57.0 & $\begin{aligned} 0.0-58.0 \\
0.011\end{aligned}$ & - \\
\hline Pectin substances & 0.9 & $0.8-1.1$ & \\
\hline Monosaccharides, \% & 2.8 & & \\
\hline 7 Vitamins, mg/\% & & & \\
\hline A (carotene) & Traces & & \\
\hline $\mathrm{C}(\operatorname{vitamin} \mathrm{C})$ & Traces & & \\
\hline E (tocopherols) & Traces & $003-0.05$ & \\
\hline F (unsaturated acids) & 1.22 & & \\
\hline P (bioflavonoids) & 0.04 & & \\
\hline $\begin{array}{l}8 \text { The amount of micro-, macroelements, } \\
\%\end{array}$ & 1.21 & $1.16-1.26$ & - \\
\hline
\end{tabular}

The grinding technology allows the production of high-quality fine powders from cheap raw materials, including in the framework of secondary processing and reactivation of building materials, paints, rubber, metals. The proposed grinding technology allows us to produce fine, high-quality powders from almost any type of materials or waste of economic entities. Powdered concentrates have potential in almost all areas of industry, from household chemicals to nuclear power [10,13]. Large volumes of waste in agricultural production make it possible to use them in various sectors of the national economy.

\section{Conclusions}

The developed and presented grinding technology testifies to the optimal composition of macroand microelements in agricultural raw materials. On its basis, the authors have created a feed additive for cattle. The results of the experiments on the use of a feed additive characterize it as effective from the standpoint of technical and economic parameters. The research carried out is the basis for the development of the concept of the powder industry for the agricultural sector.

Within the framework of the proposed concept, priority directions for research and development in the subject area under consideration are identified for the long and short term. It will become a reference point for all development institutions related to research and development, as well as to achieve a synergistic effect from the investments of the state and private companies in research and development. Areas for further research on the use of nanopowders are:

- recycling and waste-free production in the industrial sector and at the enterprises of the agricultural complex;

- developments in the field of food powders for functional nutrition and molecular cuisine;

- production of powder dyes based on natural materials of plant and animal origin.

- The implementation of the concept will allow: 
- to modernize the existing production of powdered concentrates or to organize the construction of fundamentally new production facilities for the technology and method of preparing dry fine powders from vegetable, animal raw materials, materials and waste;

- increase the degree of in-depth processing of organic raw materials and reduce the loss of agricultural products, improve the quality of food and recycled products;

- to bring to the market competitive and qualitatively new products made in the form of small fraction powders in industrial volumes.

\section{References}

[1] Kulikov A., Blagov A., Marchenkov N., Lomonov V.,Vinogradov A., Pisarevsky Y., Kovalchuk $\mathrm{V}$. Rearrangement of the structure of paratellurite crystals in a near-surface layer caused by the migration of charge carriers in an external electric field, JETP Letters, 2018, pp. 646-650.

[2] Boyko K., Popov V., Kovalchuk M. Promising approaches to crystallization of macromolecules suppressing the convective mass transport to the growing crystal, Russian Chem. Reviews, (84:8), 2015, pp. 853-859.

[3] Керимов М.А. Измельчительные технологии: от микроразмерных фракций до наночастиц (grinding technologies: from micro-sized fractions to nanoparticles). Proceedings of the St. Petersburg State Agrarian University, 2020, No.1 (58), pp. 166-171 (In Russian).

[4] Aufbereitungstechnik, 1988, Vol.0, pp. 563-570.

[5] Patent 1233548, F16 D 25/10, Canada.

[6] Kinta Yasuyoshi, Hatta Tamao. Composition, structure and color of fat bloom due to the partial liquefaction of fat in dark chocolate. Journal American Oil Chemistry Society. vol. 84 (2), 2007. pp. 107-115. DOI: 10.1007/s11746-006-1013-5

[7] Intipunya B., Bhandari R. Chemical Deterioration and Physical Instability of Food and Beverages, 2010 [online] [31.03.2021] Available at: https://www.sciencedirect.com/science/article/pii/B9781845694951500228

[8] Gaiani C., Burgain J., Scher J. Surface composition of foopowders, 2013, [online] [12.03.2021] Available at https://www.sciencedirect.com/science/article/pii/B9780857095138500145

[9] Cuq B., Gaiani C., Turchiuli C., Galet L., Scher J., Jeantet R., Mandato S., Petit J., Murrieta-Pazos I., Barkouti A., Schuck A., Rondet E., Delalonde M., Dumoulin E., Delaplace G., Ruiz Y. Advances in Food Powder Agglomeration Engineering 2013, [online] [04.12.2020] Available at: https://www.sciencedirect.com/science/article/pii/B9780124105409000028

[10] Cappelli A. Improving roller milling technology using the break, sizing, and reduction systems for flour differentiation, LWT, vol. 133, 2020 [online] [11.02.2021] Available at: https://www.sciencedirect.com/science/article/abs/pii/S0023643820310562

[11] Ermiş E. Zaim S. Food Powders Properties and Characterization, 2021, [online] [14.03.2021] Available at: https://www.springer.com/gp/book/9783030489076

[12] Bhandari B. and Roos Y. Food materials science and engineering, 2012, In book: Food Materials Science and Engineering, pp. 1-25.

[13] Peggy W. and Comillon P. Influence of thermal conditions and presence of additives on fat bloom in chocolate. Journal American Oil Chemistry Society, vol. 78 (9), 2001, pp. 927-932 DOI: $10.1007 / \mathrm{s} 11746-001-0365-1$ 